\title{
SSR fingerprinting of raspberry cultivars traded in Germany clearly showed that certainty about the genotype authenticity is a prerequisite for any horticultural experiment
}

\author{
D. Pinczinger, M. von Reth, M.-V. Hanke and H. Flachowsky
}

Julius Kühn-Institut (JKI), Federal Research Centre for Cultivated Plants, Institute for Breeding Research on Fruit Crops, Dresden, Germany

\begin{abstract}
Summary
Raspberry (Rubus idaeus L.) cultivars are propagated vegetatively, as many other fruit species from the Rosaceae family. During propagation, mistaken identities of cultivars can be caused by mislabelling plants for various reasons. This poses a problem not only for growers who buy cultivars because of specific characteristics (e.g., resistance) but also for breeders who are being deprived of licensing fees for cultivars under Plant Variety Protection (PVP). In this study, six raspberry cultivars of up to six different origins were tested for trueness-to-type by fingerprinting with 16 SSR markers. Nine out of 33 samples turned out not to be true-to-type, seven from online shops and two from nurseries.
\end{abstract}

Keywords

genotyping, horticulture, Plant Variety Protection, Rosaceae, small fruit, trueness-to-type

\section{Introduction}

The evaluation of cultivars on economically important traits represents one of the standard experimental approaches in horticultural science. Results of such evaluation trials are commonly used to recommend cultivars for cultivation in certain regions, for selected cultivation systems or to answer scientific questions in horticultural and breeding research. The benefit of those experiments strongly depends on the experimental design, the methods applied, and the certainty on trueness-to-type of all genotypes used for evaluation. Mix-ups of genotypes which can unintentionally occur and which often remain undetected will inevitably lead to wrong conclusions and, in the worst-case scenario, to fatal consequences.

In practice, nobody would doubt the trueness-to-type of plant material, which is provided by genebanks or commercial plant retailers. However, the results of the present study, which was performed on red raspberry, clearly show that trueness-to-type is never guaranteed and needs to be tested before starting any horticultural experiment.

Red raspberry (Rubus idaeus L.), is a temperate small fruit grown both commercially and in private gardens. For commercial fruit production, raspberry plants are usually sold in large quantities by specialized nurseries and plant retailers. The number of those companies is rather small in Europe, as red raspberry does not belong to the leading crops in commercial fruit production. Further reasons for the com-

\section{Significance of this study}

What is already known on this subject?

- Red raspberry cultivars are different in their resistance, adaptation to local climate and fruit qualities, hence the importance of trueness-to-type.

What are the new findings?

- The extent of mislabelled plants is higher than previously thought.

What is the expected impact on horticulture?

- Genotyping newly acquired cultivars may be necessary to ensure the validity of horticultural experiments and with planting commercial plots.

paratively small number of plant retailers are the limited production area, the low number of cultivars successfully grown in commercial raspberry fruit production, and the expenses that have to be paid to breeders for plant propagation licenses. For private gardens, a wider spectrum of cultivars is sold, including new, but also traditional and locally adapted cultivars. As with many other crops, new alternatives to traditional acquisition from nurseries are appearing in the form of online sources. This is especially the case for raspberry plants sold in small quantities for private use. The latter outlets obtain their propagated plant material from their own nursery or act as re-sellers of material obtained from large nurseries.

Like most fruit crops from the Rosaceae plant family, raspberries are propagated vegetatively. Vegetative propagation of raspberries in the field is commonly realised through root cuttings or by root suckers. For root cuttings new canes emerge from shoot buds of root pieces that have been cut off from so-called mother plants and planted. For suckering, canes have already emerged from the shoot buds at the time of propagation (Rieger, 2007). As some raspberry cultivars can generate a prolific number of suckers on their sprawling root system, great care is to be taken to prevent cultivar mixups (Janick, 2009).

Trueness-to-type in raspberry cultivation is important for several reasons, including plant health and overgrowth as well as fruit quality and shelf life. For example, plant health can be severely compromised if the acquired genotype's resistance or climate requirements deviate from the intended cultivar's attributes. Additionally, cultivars with a high propensity for suckering can take over genotypes that make less suckers. There were instances of cultivar mix-ups negative- 
ly impacting raspberry plant production, for example when 'Glen Shee' was mistaken as 'Glen Ample' in the UK. Another mix-up happened when a 'Meeker' stock was contaminated with 'Willamette' in the Pacific Northwest. Even though the contamination was only $1 \%$ it resulted in no certification until it was completely eliminated (Janick, 2009). Finally, as shelf-life can differ amongst cultivars (Haffner et al., 2002), fruit from a mixture of cultivars in one container will limit the storage ability to the fruit with the shortest shelf life. Identification of possible mix-ups by phenotype alone is often difficult since fruits appear on plants months after they have been planted.

DNA-fingerprinting allows the unambiguous identification of cultivars at the vegetative stage by employing molecular markers (Rongwen et al., 1995). Simple sequence repeat (SSR) markers make use of tandem repeat DNA patterns, which are most frequently found in the untranslated regions of eukaryotic genomes and which are prone to mutations (Levinson and Gutman, 1987; Litt and Luty, 1989; Vieira et al., 2016). Therefore, the polymorphic marker patterns of SSRs are ideally suited for genotyping on the cultivar level. DNA fingerprinting of raspberry cultivars using SSR markers was successfully done by Bassil et al. (2012), Bradish et al. (2016), Dossett et al. (2012), and Girichev et al. (2015). Girichev et al. (2015) established DNA fingerprints for 82 Rubus genotypes available in German germplasm collections, nurseries and home gardens using a set of 16 commonly used SSR markers. As most of the commercially sold raspberry cultivars were also among the 82 Rubus genotypes, the data provided by Girichev et al. (2015) represent a great baseline for cultivar identification and evaluations on trueness-to-type.

To verify the level of cultivars that are sold true-to-type in Germany, samples of six different raspberry cultivars were ordered from a total of 14 different nurseries and online suppliers. These samples were tested using the set of 16 SSR-markers. The DNA fingerprint profiles were compared among the samples, but also with samples, which are known to be true-to-type to prove their cultivar authenticity.

\section{Materials and methods}

\section{Plant material}

Plants of the six raspberry cultivars 'Glen Ample', 'Meeker,, 'Polka', 'Preußen', 'Schönemann', and 'Tulameen' were acquired as potted single plants. A total of five to six samples per cultivar were ordered from seven different nurseries (designated by capital letters: B, E, F, H, J, K, and L) and sev- en online shops (designated by lowercase letters: a, c, d, g, i, $\mathrm{m}$, and $\mathrm{n}$ ), respectively. All plants were grown in pots at the experimental field of the Julius Kühn-Institut (JKI), Dresden Pillnitz (Germany). Leaf material of each plant was harvested and used for the isolation of genomic DNA. Leaf samples of plants grown at the German Federal Plant Variety Office in Wurzen, which are known to be true-to-type, were used as positive controls (P). An overview about the plant material used in this study is given in Table 1.

\section{DNA isolation and SSR marker analysis}

Young leaf material (0.1 g) was processed with the DNeasy Plant Mini Kit (Qiagen, Hilden, Germany) following the manufacturer's protocol to extract genomic DNA, which was then re-suspended in $50 \mu \mathrm{L}$ of the elution buffer included in the kit. A working solution was diluted with $\mathrm{ddH}_{2} \mathrm{O}$ to $10 \mathrm{ng} \mu \mathrm{L}^{-1}$ for the use in the polymerase chain reaction (PCR). Sixteen simple sequence repeat (SSR) markers chosen from Castillo et al. (2010) and Fernandez-Fernandez et al. (2011) were divided into six multiplexes (Table 2). Ten ng of genomic DNA was used as template and amplified with the Type-it Microsatellite PCR Kit (Qiagen, Hilden, Germany) in a reaction volume of $10 \mu \mathrm{L}$ per sample. The concentration for both forward and reverse primers was $0.2 \mu \mathrm{M}$ for primers with Dye-751, $0.1 \mu \mathrm{M}$ for primers labelled with BMN-6 and $0.05 \mu \mathrm{M}$ for primers with BMN-5 fluorescent labelling. All primers were ordered at biomers.net GmbH (Ulm, Germany). The annealing temperature of the multiplexes was $\mathrm{A}: 57^{\circ} \mathrm{C}$, B: $51^{\circ} \mathrm{C}, \mathrm{C}: 52^{\circ} \mathrm{C}, \mathrm{D}: 57^{\circ} \mathrm{C}, \mathrm{E}: 52^{\circ} \mathrm{C}$ and F: $51^{\circ} \mathrm{C}$. The PCR program was as follows: initial denaturation at $95^{\circ} \mathrm{C}$ for $5 \mathrm{~min}$, 28 cycles of $95^{\circ} \mathrm{C}$ for $1 \mathrm{~min}$, annealing for $90 \mathrm{~s}$ and $72^{\circ} \mathrm{C}$ for $30 \mathrm{~s}$, with a final extension step of $60^{\circ} \mathrm{C}$ for $30 \mathrm{~min}$.

The PCR product was diluted 1:20 with $\mathrm{ddH}_{2} \mathrm{O}$ and $1 \mu \mathrm{L}$ was added to $24.9 \mu \mathrm{L}$ SLS buffer and $0.1 \mu \mathrm{L} 400 \mathrm{bp}$ size standard per reaction in the capillary electrophoresis plate. A drop of mineral oil was added to prevent evaporation. All samples were evaluated with the CEQ 8800 Genetic Analysis capillary electrophoresis system (Beckman Coulter, Krefeld, Germany). The resulting marker profiles were inspected visually through the CEQ 8800 software of the same supplier. Failed reactions were repeated with samples that worked in previous runs as positive controls.

Statistical analysis was conducted with GenAlEx 6.5 (Peakall and Smouse, 2012). Probability of Identity was calculated with 15 marker data from the positive controls, samples with marker profile not fitting their expected fingerprints and 75 cultivars genotyped by Girichev et al. (2015),

TABLE 1. Samples of different raspberry cultivars used in this study. As positive controls, samples of each cultivar were obtained from the Federal Plant Variety Office Wurzen (P). Different nurseries are indicated by capital letters, whereas lowercase letters indicate different online suppliers. The real names of nurseries and online suppliers are not provided to avoid any damage to business. Samples that were found to be wrongly labelled are shown in bold.

\begin{tabular}{|c|c|c|c|c|}
\hline \multirow{2}{*}{ Cultivar } & \multicolumn{3}{|c|}{ Origin } & \multirow{2}{*}{ Number of samples ${ }^{1}$} \\
\hline & Wurzen & Nursery & Online shop & \\
\hline Glen Ample & $P$ & $\mathrm{~B}, \mathrm{~F}$ & $a, c, d, m$ & 6 \\
\hline Meeker & $P$ & $B, E, L$ & $a, c$ & 5 \\
\hline Polka & $P$ & $\mathrm{~B}, \mathrm{H}$ & $a, \mathbf{c}, \mathbf{n}$ & 5 \\
\hline Preußen & $P$ & $\mathrm{~B}, \mathrm{~K}$ & $a, c, i$ & 5 \\
\hline Schönemann & $P$ & $B, J$ & $a, c, g, m$ & 6 \\
\hline Tulameen & $\mathrm{P}$ & $\mathrm{B}, \mathrm{F}$ & $a, c, d, m$ & 6 \\
\hline Total & & & & 33 \\
\hline
\end{tabular}

${ }^{1}$ Number of individual plant samples obtained from nurseries and online shops (positive controls are not included). 
TABLE 2. SSR markers used in this study. The table contains information on the name, the forward and reverse sequences of the primers used for each marker, the linkage group where the marker was genetically mapped and the fluorescent label of each SSR marker used in the multiplex PCR reactions.

\begin{tabular}{|c|c|c|c|c|}
\hline Multiplex & Primer & Sequence $\left(5^{\prime} \rightarrow 3^{\prime}\right)$ & Linkage group & Label \\
\hline \multirow[t]{6}{*}{ A } & RhM043 & GGACACGGTTCTAACTATGGCT & $4^{2}$ & BMN-5 \\
\hline & & ATTGTCGCTCCAACGAAGATT & & \\
\hline & RiM017 & GAAACAGGTGGAAAGAAACCTG & $7^{2}$ & BMN-6 \\
\hline & & CATTGTGCTTATGATGGTTTCG & & \\
\hline & RhM011 & AAAGACAAGGCGTCCACAAC & $7^{2}$ & Dye-751 \\
\hline & & GGTTATGCTTTGATTAGGCTGG & & \\
\hline \multirow[t]{6}{*}{ B } & RiM019 & ATTCAAGAGCTTAACTGTGGGC & $5^{2}$ & BMN-5 \\
\hline & & CAATATGCCATCCACAGAGAAA & & \\
\hline & RhM001 & GGTTCGGATAGTTAATCCTCCC & $2^{2}$ & BMN-6 \\
\hline & & CCAACTGTTGTAAATGCAGGAA & & \\
\hline & RhM021 & CAGTCCCTTATAGGATCCAACG & $5^{2}$ & Dye-751 \\
\hline & & GAACTCCACCATCTCCTCGTAG & & \\
\hline \multirow[t]{6}{*}{ C } & RiM036 & AGCAACCACCACCTCAACTAAT & & BMN-5 \\
\hline & & CTAGCAGAATCACCTGAGGCTT & & \\
\hline & RhM023 & CGACAACGACAATTCTCACATT & & BMN-6 \\
\hline & & GTTATCAAGCGATCCTGCAGTT & & \\
\hline & RhM003 & ССАТСТССААТTCAGTTСTTCC & $2^{2}$ & Dye-751 \\
\hline & & AGCAGAATCGGTTCTTACAAGC & & \\
\hline \multirow[t]{4}{*}{$\mathrm{D}$} & RiM015 & CGACACCGATCAGAGCTAATTC & $3^{2}$ & BMN-5 \\
\hline & & ATAGTTGCATTGGCAGGCTTAT & & \\
\hline & RiG001 & TGTCCGATCCTTTTCTTTGG & & BMN-6 \\
\hline & & СGCTTCTTGATCCTTGACTTGT & & \\
\hline \multirow[t]{4}{*}{$\mathrm{E}$} & Rubus123a & CAGCAGCTAGCATTTTACTGGA & $6^{1}$ & BMN-6 \\
\hline & & GCACTCTCCACCCАTTTCAT & & \\
\hline & Rubus285a & TCGAGAAGCTTGCTATGCTG & $1^{1}$ & BMN-5 \\
\hline & & GGATACCTCAATGGCTTTCTTG & & \\
\hline \multirow[t]{6}{*}{$\mathrm{F}$} & Rubus223a & TCTCTTGCATGTTGAGATTCTATT & $3^{1}$ & BMN-5 \\
\hline & & TTAAGGCGTCGTGGATAAGG & & \\
\hline & Rubus270a & GCATCAGCCATTGAATTTCC & $2^{1}$ & BMN-6 \\
\hline & & СССАССТССАТТАССААСТС & & \\
\hline & Rubus275a & CACAACCAGTCCCGAGAAAT & $5^{1}$ & Dye-751 \\
\hline & & САТTTCATCCAAATGCAACC & & \\
\hline
\end{tabular}

${ }^{1}$ Castillo et al., 2010.

2 Fernandez-Fernandez et al., 2011.

90 samples in all. The neighbour joining phylogenetic tree was calculated with DARwin 6.0.21 (Perrier et al., 2003) with 1,000 bootstrap replicates and the genetic distance data from all 39 samples used in this study.

\section{Results}

Using the 16 SSR markers a total of 69 different alleles were detected in this study. The amplified allele sizes ranged between 112 and $377 \mathrm{bp}$ with up to eight alleles per locus (Table 3). Marker RhM023 was monomorphic for all six cultivars. Fourteen markers amplified at least two different alleles within the tested cultivars. Marker RiG001 amplified no fragment for the cultivar 'Meeker', whereas marker RiM036 delivered no fragments with any of the cultivars.

The DNA-fingerprint pattern of all six samples of 'Glen Ample' and 'Meeker' was identical to the pattern of the positive controls. All samples of these two cultivars were trueto-type. Of the remaining 22 samples of 'Polka', 'Preußen', 'Schönemann', and 'Tulameen' only 13 were identical to sam- ples used as control. Nine samples (Table 3) expressed marker pattern that differed from the pattern expected for the respective cultivar. They were found to be not true-to-type. Seven of these samples were obtained from five different online shops (a, c, d, m, and n), whereas two samples originated from nursery B (Table 3). One sample that was sold as 'Polka' expressed a DNA-marker profile fitting to 'Meeker'. Two samples sold as 'Preußen' expressed DNA-marker profiles fitting to 'Meeker' and 'Tulameen', respectively. Two samples sold as 'Schönemann' showed a DNA-marker profile that is very similar, but not identical to 'Schönemann'. The remaining samples that were found to be not true-to-type had an unknown DNA fingerprint profile.

Probability of Identity is under 0.05 after application of the first four markers (Figure 1). The Neighbour joining cluster analysis shows 'Meeker' having greater genetic distance to the other five cultivars, with these five cultivars being in a cluster together (Figure 2). 


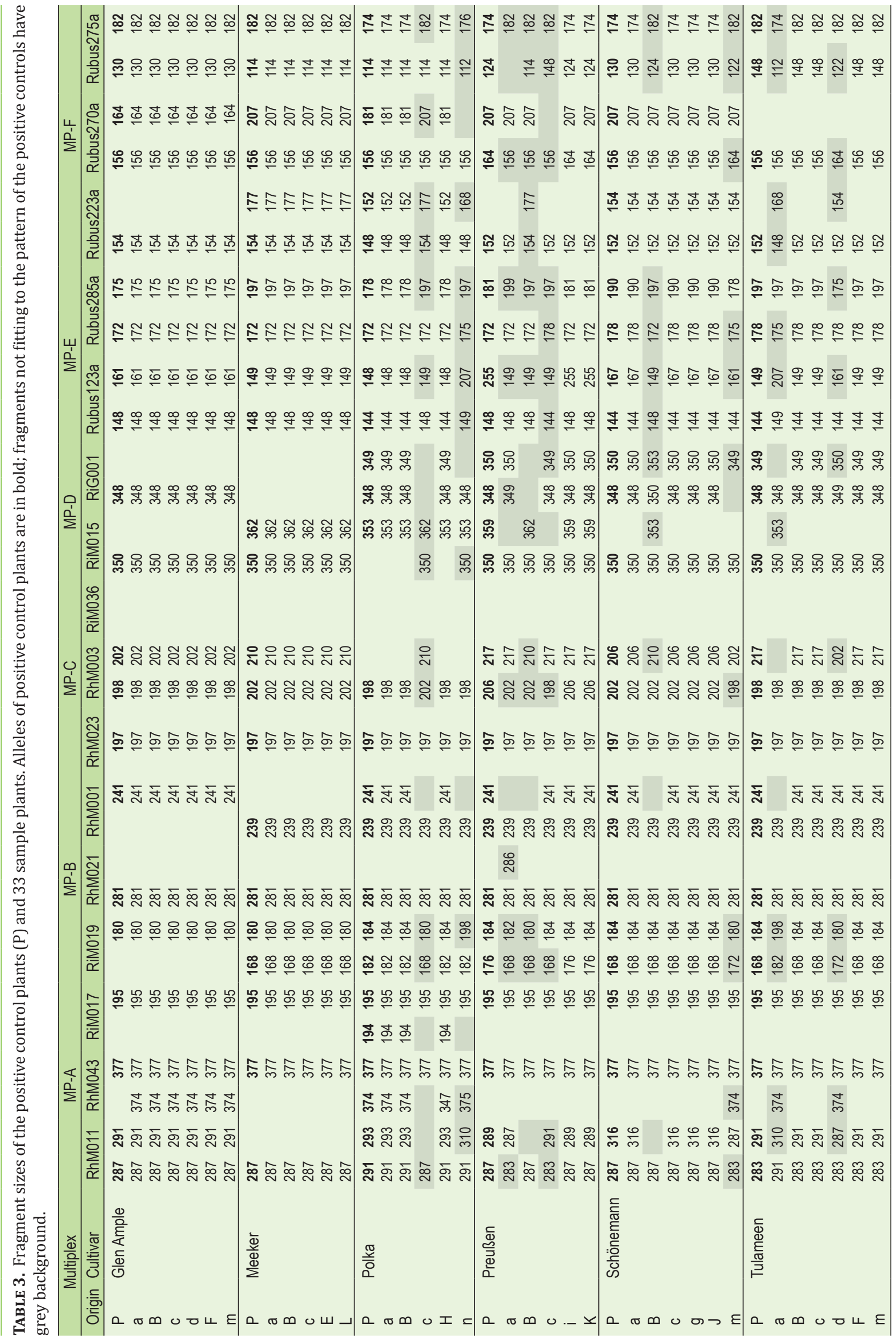




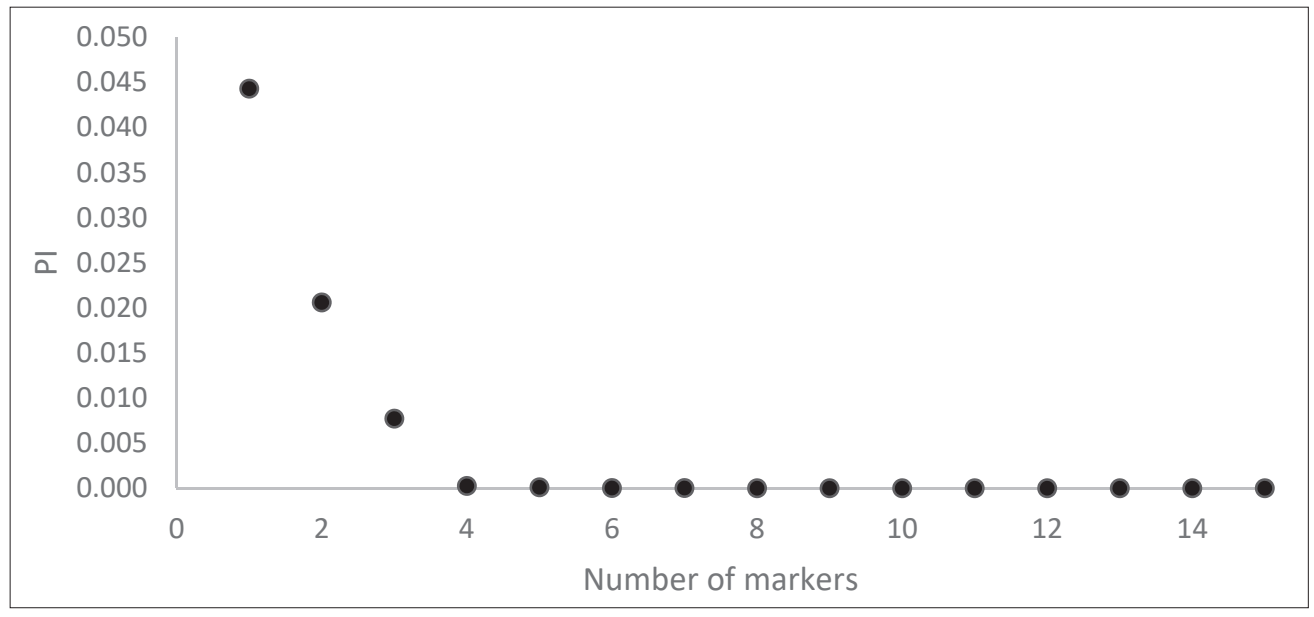

FIGURE 1. Probability of Identity (PI) of markers applied on positive control plants, plants that were not true-totype and 75 cultivars, published by Girichev et al. (2015). PI was calculated from the allele frequency of 15 markers on 90 samples.

\section{Discussion}

As cultivar identity is an important issue for nurserymen, plant retailers, fruit growers, and horticultural scientists, 33 samples of six different raspberry cultivars were ordered from different nurseries and online shops and tested using a set of 16 SSR-markers on trueness-to-type. In parallel samples of five cultivars which originated from the collection of the Federal Plant Variety Office were also tested. As plants of this collection are assumed to be true-to-type, these samples were used as control. DNA fingerprints of the control samples were compared to fingerprints published recently by Girichev et al. (2015). Surprisingly, only three out of the five control samples amplified marker profiles that were identical to the fingerprints of the published study. For the cultivar 'Polka' no published fingerprint data was available for comparison. 'Glen Ample', 'Schönemann', and 'Tulameen' were fitting the published fingerprints, although some few marker alleles were shifted by $1 \mathrm{bp}$. The differences found for 'Meeker' and 'Preußen' suggest that the samples genotyped by Girichev et al. (2015) were not true-to-type. This is supported by the fact that Girichev et al. (2015) failed to confirm the fingerprints of these two cultivars by proving their parent-offspring relationships.

Subsequently, all 33 samples of the commercially sold plants were tested. Whereas 24 samples appeared to be true-to-type, nine samples were found to be wrongly labelled. Their DNA-marker profiles differed from the profiles expected for the cultivars whose names were mentioned on the label provided along with the given plant samples. Those differences in the DNA-marker profile can stem from cultivar mix-ups, spontaneous mutations or technical errors during analysis. As all of the differing marker profiles detected in this study had more than one marker disparity, spontaneous mutation is unlikely the source of mismatch. As for technical errors, results could be interpreted wrong when a primer has lost its fluorescence, as it happened with RiM036 in this study. However, as the differences to the expected alleles are not of this nature, technical error as cause can be excluded as well.

On this account an unwanted mix-up that has possibly occurred during propagation or shipping is the most likely reason. A mix-up with a completely different cultivar could occur during both stages. Canes of a different cultivar could grow through from a neighboring row and thus be collected with the wrong cultivar during propagation. Mistakes during propagation in vitro are also possible. A mix-up during shipping could stem from mislabelling of packed plant ma-

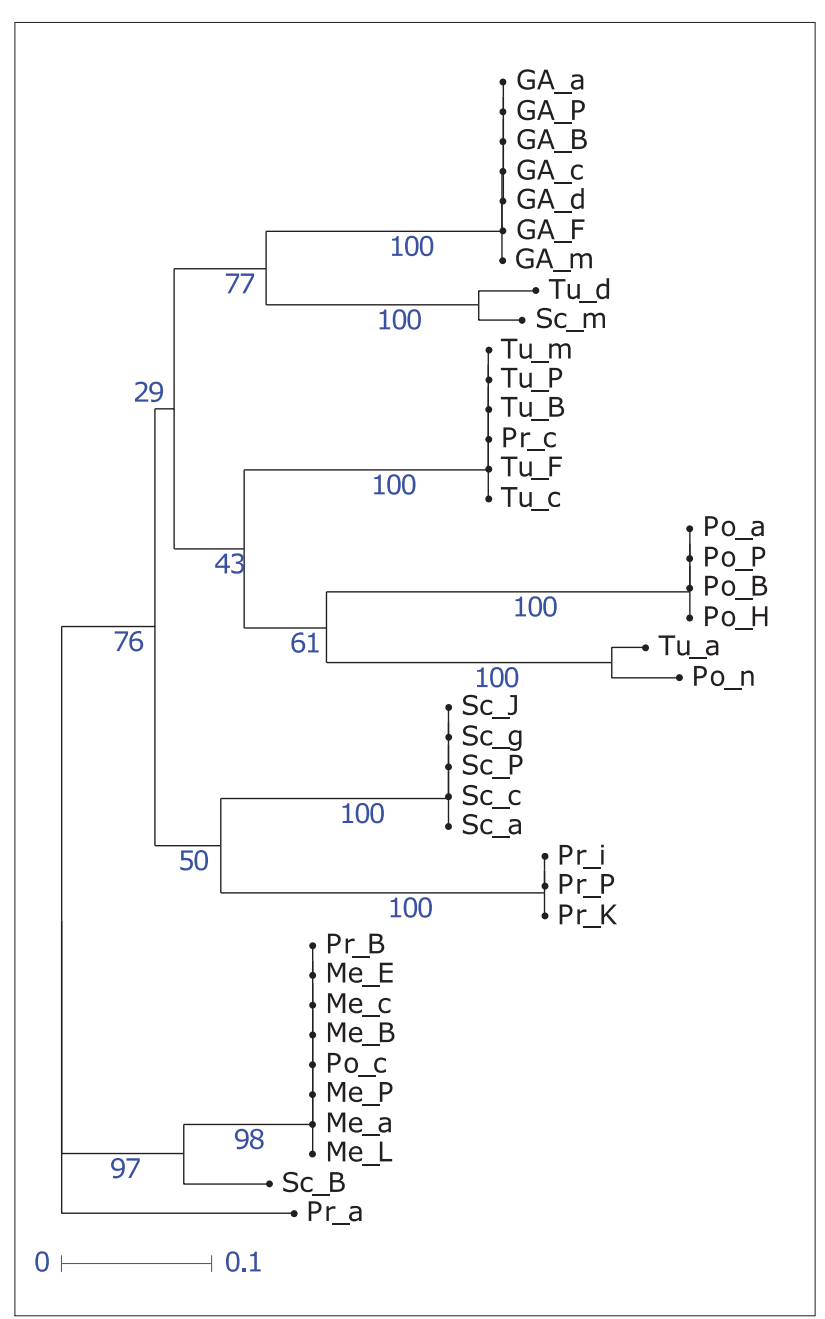

FIGURE 2. Neighbour joining phylogenetic tree of positive control plants (P) and 33 sample plants. The dendrogram was calculated from the genetic distance of 39 samples using allele sizes of 15 loci. GA: 'Glen Ample', Me: 'Meeker', Po: 'Polka', Pr: 'Preußen', Sc: 'Schönemann', Tu: 'Tulameen'.

terial. The remaining unknown profiles, together with the 'Schönemann'-like profiles did not match any of the cultivars with available SSR-marker fingerprints (Girichev et al., 2015). They could originate from a cultivar not in that list or a progeny of a crossing. In the case of the two plants which 
are very similar to 'Schönemann', although their marker profile is similar to the positive control, they cannot be a direct progeny due to some of their markers not containing any of 'Schönemann's alleles. The genetic distance of the not trueto-type plants with unknown profiles points to a mix-up with a different cultivar or unknown crossing as well, as they are all not in the near vicinity to their supposed cultivar.

Fourteen polymorphic markers were used for differentiation between cultivars. All seven linkage groups were represented with at least one marker (Castillo et al., 2010; Fernandez-Fernandez et al., 2011). Other cultivar identification studies were conducted with 14 markers in hazelnut (Akin et al., 2016) and in pistachio (Ahmad et al., 2003), in grapevine even 9, although in the latter combined with description and photos (Maul et al., 2015). Although the focus of these aforementioned studies was not the testing of trueness-to-type, sample discrepancies within cultivars were still found in the studies of Maul et al. (2015) and Akin et al. (2016). As red raspberry cultivars have a small genetic diversity (Girichev et al., 2015), not only the number but the extent of polymorphism of the SSR markers is important. As the Probability of Identity is under 0.05 after using only four markers, the 15 markers used in this study should be more than sufficient to ensure reliable cultivar identification.

Dossett et al. (2012) found in their study that several black raspberry cultivars had differing SSR marker profiles even among the same source. Additionally, cultivars 'Jewel' and 'Allen' did not match their reported pedigree. Bassil et al. (2012) reported similar issues with red raspberry cultivars, concluding the different SSR marker profiles stem from somaclonal variation with 'Meeker' and a cultivar mix-up with 'Cuthbert'.

The present study raises awareness of a problem that could be of a bigger extent than previously assumed. At least in some cases Plant Variety Protection Rights could become violated. However, the sampling size of this study is limited and demands further study of the extent of mix-ups in the sale of raspberry cultivars. The tendency of mix-ups was higher in the case of online shops than with the direct sourcing from nurseries. In nurseries, trained personnel can more easily spot a difference in the appearance and thus figuring out a mix-up before a sale can take place. Additionally, the time constraint that a purely online business puts on the shipping process is conducive to errors.

This information could be particularly useful for growers who find trueness-to-type important enough for the higher cost of direct nursery sourcing, where the corresponding training and diligence could prevent more mix-ups than with online shop personnel. Furthermore, this study underlines the necessity of DNA fingerprinting for growers, breeders and propagators alike.

\section{Acknowledgments}

We gratefully acknowledge the Federal Ministry of Food and Agriculture (BMEL) for the financial support (Project Number: 313-06.01-28DIP2-2814IP014) in the frame of supporting innovation in plant breeding by the Federal Office for Agriculture and Food (BLE). We would also like to express our gratitude to I. Polster, V. Vogt and R. Gläß for technical assistance. We also acknowledge Dr. F.O. Emeriewen for improving the English language of the manuscript.

The authors acknowledge E. Schulte of the German Federal Plant Variety Office (Wurzen, Germany) for providing leaf material of the control samples.

\section{References}

Ahmad, R., Ferguson, L., and Southwick, S.M. (2003). Identification of Pistachio (Pistacia vera L.) nuts with microsatellite markers. J. Am. Soc. Hortic. Sci. 128, 898-903. https://doi.org/10.21273/ JASHS.128.6.0898.

Akin, M., Nyberg, A., Postman, J., Mehlenbacher, S., and Bassil, N.V. (2016). A multiplexed microsatellite fingerprinting set for hazelnut cultivar identification. Eur. J. Hortic. Sci. 81, 327-338. https://doi. org/10.17660/eJHS.2016/81.6.6.

Bassil, N.V., Nyberg, A., Hummer, K.E., Graham, J., Dossett, M., and Finn, C.E. (2012). A universal fingerprinting set for red raspberry. Acta Hortic. 946, 83-87. https://doi.org/10.17660/ ActaHortic.2012.946.10.

Bradish, C.M., Overbaugh, E., Ballington, J., Fernandez, G.E., and Bassil, N.V. (2016). Comparative diversity analysis of southeastern Rubus germplasm through molecular and pedigree techniques. Acta Hortic. 1127, 157-162. https://doi.org/10.17660/ ActaHortic.2016.1127.25.

Castillo, N.R.F., Reed, B.M., Graham, J., Fernandez-Fernandez, F., and Bassil, N.V. (2010). Microsatellite markers for raspberry and blackberry. J. Am. Soc. Hortic. Sci. 135, 271-278. https://doi. org/10.21273/JASHS.135.3.271.

Dossett, M., Bassil, N.V., and Finn, C.E. (2012). SSR fingerprinting of black raspberry cultivars shows discrepancies in identification. Acta Hortic. 946, 49-53. https://doi.org/10.17660/ ActaHortic.2012.946.4.

Fernandez-Fernandez, F., Antanaviciute, L., Govan, C.L., and Sargent, D.J. (2011). Development of a multiplexed microsatellite set for fingerprinting red raspberry (Rubus idaeus) germplasm and its transferability to other Rubus species. J. Berry Res. 1, 177-187. https://doi.org/10.3233/JBR-2011-019.

Girichev, V., Hanke, M.-V., Peil, A., and Flachowsky, H. (2015). SSR fingerprinting of a German Rubus collection and pedigree based evaluation on trueness-to-type. Genet. Resour. Crop Evol. 64, 189203. https://doi.org/10.1007/s10722-015-0345-0.

Haffner, K., Rosenfeld, H.J., Skrede, G., and Wang, L. (2002). Quality of red raspberry Rubus idaeus L. cultivars after storage in controlled and normal atmospheres. Postharvest Biol. Technol. 24, 279-289. https://doi.org/10.1016/S0925-5214(01)00147-8.

Janick, J. (2009). Plant Breeding Reviews, Vol. 32 (John Wiley \& Sons), p. 117-118, 123. https://doi.org/10.1002/9780470593783.

Levinson, G., and Gutman, G.A. (1987). Slipped-strand mispairing: A major mechanism for DNA sequence evolution. Mol. Biol. Evol. 4 203-221.

Litt, M., and Luty, J.A. (1989). A hypervariable microsatellite revealed by in vitro amplification of a dinucleotide repeat within the cardiac muscle actin gene. Am. J. Hum. Genet. 44, 397-401.

Maul, E., Toepfer, R., Carka, F., Cornea, V., Crespan, M., Dallakyan, M., de Andres Dominguez, T., de Lorenzis, G., Dejeu, L., Goryslavets, S., et al. (2015). Identification and characterization of grapevine genetic resources maintained in Eastern European Collections. Vitis 54, 5-12.

Peakall, R., and Smouse, P.E. (2012). GenAlEx 6.5: genetic analysis in Excel. Population genetic software for teaching and research - An update. Bioinformatics 28, 2537-2539. https://doi.org/10.1093/ bioinformatics/bts460.

Perrier, X., Flori, A., and Bonnot, F. (2003). Data analysis methods. In Genetic Diversity of Cultivated Tropical Plants (Enfield, Montpellier: CIRAD, Science Publishers), p. 43-76.

Rieger, M. (2007). Introduction to Fruit Crops (Bosa Roca: Taylor \& Francis Inc.), p. 97. https://doi.org/10.1201/9781482298055. 
Rongwen, J., Akkaya, M.S., Bhagwat, A.A., Lavi, U., and Cregan, P.B. (1995). The use of microsatellite DNA markers for soybean genotype identification. TAG Theor. Angew. Genet. 90, 43-48. https://doi. org/10.1007/BF00220994.

Vieira, M.L.C., Santini, L., Diniz, A.L., and Munhoz, C. de F. (2016). Microsatellite markers: what they mean and why they are so useful. Genet. Mol. Biol. 39, 312-328. https://doi.org/10.1590/1678-4685GMB-2016-0027.

Received: Feb. 1, 2019

Accepted: May 15, 2019

Address of authors:

Dora Pinczinger*, Marcel von Reth, Magda-Viola Hanke and Henryk Flachowsky

Julius Kühn-Institut (JKI), Federal Research Centre for Cultivated Plants, Institute for Breeding Research on Fruit Crops, Pillnitzer Platz 3a, 01326 Dresden, Germany

* Corresponding author; E-mail: pinczinger.d@gmail.com

Tel.: 0049394647 8030; Fax: 00493946478002 